\title{
Modelling of intensity-duration-frequency curves for Lahore City using frequency analysis
}

\author{
R. Ahmed \& S. Ali \\ Department of Civil Engineering, \\ National University of Computer and Emerging Sciences, Pakistan
}

\begin{abstract}
Intensity duration frequency curves are an important tool in calculating the rainfall intensities for various return period and storm durations. Normal distribution, lognormal distribution, Gumbel extreme value type 1 distribution and log Pearson distribution were used to derive the IDF curves for the region of Lahore City. 24 hours' data was processed using an Indian meteorological formula to obtain rainfall intensities for durations of $1,2,3,6,12$ and 18 hours, due to the lack of rainfall records. These records were used further to develop IDF curves. Intensity duration frequency curves show the relationship between the rainfall intensity (yaxis) and duration of rainfall event (x-axis), with a separate curve for each return period. IDF curves were plotted for the return periods of 2, 5, 10, 25 and 50. Rainfall intensities obtained from each distribution were used to calculate the values of parameters in rainfall intensities formula.

Keywords: IDF curves, rainfall duration, rainfall intensity, return periods, Lahore City, probability distribution, goodness of fit, Indian meteorological formula.
\end{abstract}

\section{Introduction}

The advent of urbanization in Lahore City has led to an increased generation of storm water runoff. The increase of grey area in the city is changing Lahore into a flood prone area during the season of monsoon. The presence of storm water on surfaces causes a hindrance in the normal human activity and damage to infrastructure. In order to manage the surface storm water generated on the pavements of the city, a proper water drainage system is required to deal with peak flow caused by an intense rainfall in monsoon season. 
The design of storm water drainage systems requires calculating the volume of storm water runoff generated in a particular region. Intensity duration frequency curves are used in order to find out the design rainfall intensity for design of a water system. IDF curves present rainfall intensity as a function of storm water duration and return period for a specific region. Probability distributions such as Normal distribution, Log-normal distribution, Gumbel extreme value type 1 and Log-Pearson Distribution type 3 are used to develop intensity duration frequency curves.

\section{Methodology}

\subsection{Study area and data collection}

Lahore city is the 2nd largest metropolitan city of Pakistan and 16th most populous city in world. It is located between $31^{\circ} 15^{\prime}$ to $31^{\circ} 45^{\prime} \mathrm{N}$ and $74^{\circ} 01^{\prime}$ to $74^{\circ} 39^{\prime} \mathrm{E}$. The Ravi River flows on the northern side of Lahore. Lahore city covers a total land area of 404 square kilometers (156 sq. mi) and expanding its limits. Rainfall data for Lahore region was collected from Pakistan Meteorological Department, Jail Road, Lahore. Rainfall data of time period 1960-2014 was collected, showing maximum rainfall depth in $\mathrm{mm}$ recorded in a day of a month. Rainfall gauge is located at Lahore Pakistan Balloon Observatory at latitude $31^{\circ} 33^{\prime}$ and longitude $74^{\circ} 20^{\prime}$. The observatory is located at an altitude of 214.00 meter above mean sea level as available from Pakistan Meteorological Department [1].

\subsection{Rainfall analysis}

Rainfall data was analyzed, to separate the maximum rainfall depth recorded in a day for a year. An annual maximum rainfall series was derived out of collected rainfall depth data. Indian meteorological department formula, eqn (1) is used to calculate rainfall depth for durations of 1-hour, 2-hour, 3-hour, 6-hour, 12-hour, 18 -hour and 24-hour. It is found in IMD empirical reduction formula provides the best estimation on short duration rainfall in Chowdary [2].

$$
P=P_{24} \times \sqrt[3]{\frac{t}{24}}
$$

$\mathrm{P}$ is the calculated rainfall depth, $\mathrm{P}_{24}$ is the rainfall and $\mathrm{t}$ represents the duration of rainfall for which the rainfall depth is being calculated. Rainfall depth was divided with their respective time periods to calculate the rainfall intensity. IMD empirical formula has been used in research papers previously [3-6].

\section{IDF curves}

Intensity duration frequency curves as discussed earlier are used to find design rainfall intensity as a function of storm duration and return period of a certain period, upon which design of the storm water system is based. Intensity duration 
frequency curves are developed for a series of storm event rather than a specific storm event. Intensity of any storm event can be represented as the sum of mean and departure from the mean. Departure of the mean is taken as equal to product of standard deviation and frequency factor $\mathrm{K}$. Thus eqn (2) " $\mathrm{P}_{\mathrm{T}}=\mathrm{P}_{\mathrm{avg}}+\mathrm{KS}$ " is obtained. The departure and frequency factor $\mathrm{K}$ are function of the return period. The frequency factor equation is given in Chow [7], which is applicable to various hydrological probability analyses.

IDF curves are developed using the following steps:

1. Series of annual maximum rainfall series of $1,2,3,6,12,18$ and 24 hours are separated from the rainfall data. Rainfall intensity is calculated for all the rainfall depths in $\mathrm{mm} / \mathrm{hr}$.

2. Mean and standard deviation for storm duration of all years is calculated. For example, mean $\left(\mathrm{P}_{\text {avg }}\right)$ using eqn (3) and standard deviation (S) using eqn (4) for annual maximum rainfall intensity series for 1 hour duration is calculated. Same process is repeated for series of 2, 3, 6, 12, 18 and 24 hours.

3. Probability distribution is used to calculate the value of constant $\mathrm{K}$ for a certain return period. Value of $\mathrm{K}$ is different for each probability distribution.

$$
\begin{gathered}
P_{\text {avg }}=\frac{\sum_{i}^{n} P_{i}}{n} \\
S^{2}=\left[\frac{1}{n-1} \sum_{i=1}^{n}\left(P_{i}-P_{\text {avg }}\right)^{2}\right]
\end{gathered}
$$

4. Then using the values of $K$, mean and standard deviation in eqn (2), rainfall intensity is calculated. A graph is plotted with rainfall duration on $\mathrm{x}$-axis and rainfall intensity on y-axis. A separate curve is obtained for each return period.

5. Graphs are analyzed to develop and empirical formula for curve. A separate empirical formula is obtained for each distribution.

\subsection{Probability distributions}

In normal and log-normal distribution, value of frequency factor $\mathrm{K}$ remains the same for both. It is calculated using the eqns (5), (6) and (7).

$$
\begin{gathered}
K=w-\frac{2.515517+0.802853 w+0.010328 w^{2}}{1+1.432788 w+0.189269 w^{2}+0.001308 w^{3}} \\
w=\left[\ln \left(\frac{1}{p^{2}}\right)\right]^{\frac{1}{2}} \\
p=\frac{1}{T}
\end{gathered}
$$

In the formula, $\mathrm{T}$ represents the return period, upon which the value of $\mathrm{K}$ depends. Value $\mathrm{K}$ is then used in equation (1) along with mean and standard 
deviation in calculated via equations (2) and (3) to calculate the rainfall intensity. In log-normal distribution, procedure is same as applied in normal distribution, except it is applied to the logarithms of variables, and their means and standard deviations area used. Following table is obtained for the log-normal distribution. Gumbel Extreme value distribution type 1 was used to derive the value of K using following eqn (8).

$$
K=-\frac{\sqrt{6}}{\pi}\left[0.5772+\ln \left[\ln \left[\frac{T}{T-1}\right]\right]\right]
$$

$\mathrm{T}$ represents the return period, for which a value of $\mathrm{K}$ is obtained. In log Pearson distribution type III, logarithms of hydrological data are obtained. This data is the used to calculate the mean, standard deviation and coefficient of skewness. The frequency factor depends on the return period and coefficient of skewness Cs.

$$
C_{S}=\frac{n \sum_{i}^{n}\left(P^{*}-P\right)^{3}}{(n-1)(n-2)\left(S^{*}\right)^{3}}
$$

The value of frequency constant $\mathrm{K}$ is obtained from the table of Pearson type III distribution in Chow [8].

Table 1: Rainfall intensity computed from normal distribution.

\begin{tabular}{|c|c|c|c|c|c|c|c|c|}
\hline$\underline{\text { Return }}$ & $\underline{\boldsymbol{Z}}$ & $\underline{\mathbf{l - h} \boldsymbol{r}}$ & $\underline{\mathbf{2 - h} \boldsymbol{r}}$ & $\underline{\mathbf{3 - h} \boldsymbol{r}}$ & $\underline{\mathbf{6 - h} \boldsymbol{r}}$ & $\underline{\mathbf{1 2 -} \boldsymbol{h} \boldsymbol{r}}$ & $\underline{\mathbf{1 8 - h} \boldsymbol{r}}$ & $\underline{\mathbf{2 4 -} \boldsymbol{h} \boldsymbol{r}}$ \\
\hline period & 2.054 & 62.838 & 39.586 & 30.209 & 19.031 & 11.989 & 9.149 & 7.552 \\
\hline 25 & 1.751077 & 58.154 & 36.635 & 27.957 & 17.612 & 11.095 & 8.467 & 6.989 \\
\hline 10 & 1.281729 & 50.900 & 32.065 & 24.470 & 15.415 & 9.711 & 7.411 & 6.117 \\
\hline 5 & 0.841457 & 44.096 & 27.778 & 21.199 & 13.354 & 8.413 & 6.420 & 5.300 \\
\hline 2 & $-1 \mathrm{E}-07$ & 31.091 & 19.586 & 14.947 & 9.416 & 5.932 & 4.527 & 3.737 \\
\hline
\end{tabular}

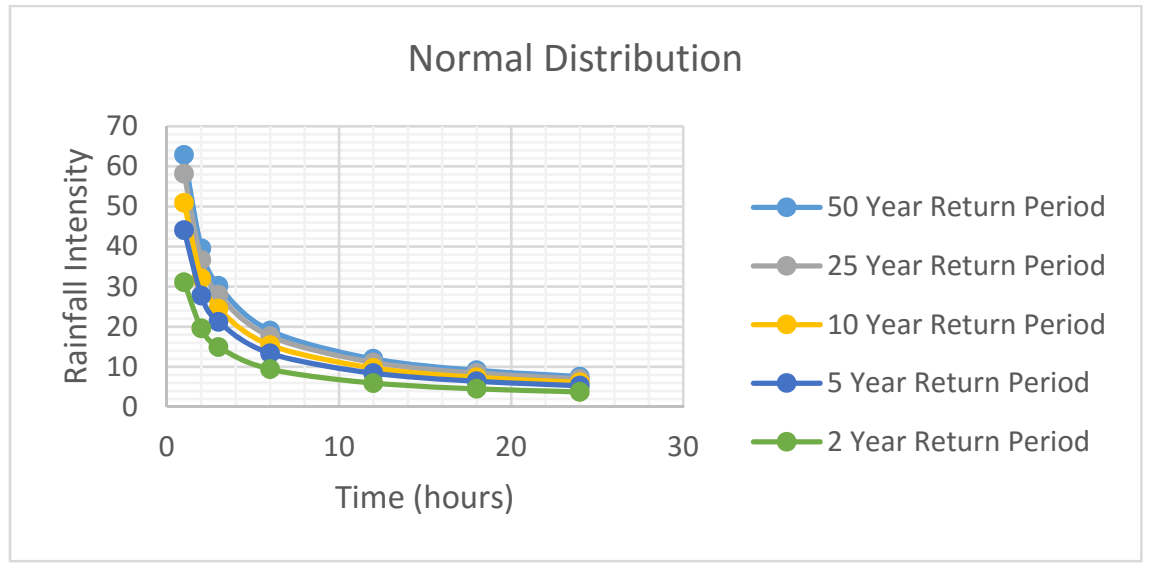

Figure 1: Intensity duration frequency curves for normal distribution. 
Table 2: Rainfall intensity computed from log normal distribution.

\begin{tabular}{|c|c|c|c|c|c|c|c|c|}
\hline$\underline{\text { Return period }}$ & $\underline{\boldsymbol{Z}}$ & $\underline{\mathbf{1 - h} \boldsymbol{r}}$ & $\underline{\mathbf{2 - h} \boldsymbol{r}}$ & $\underline{\mathbf{3 - h} \boldsymbol{r}}$ & $\underline{\mathbf{6 - h} \boldsymbol{r}}$ & $\underline{\mathbf{1 2 - h} \boldsymbol{r}}$ & $\underline{\mathbf{1 8 - h} \boldsymbol{r}}$ & $\underline{\mathbf{2 4 - h} \boldsymbol{r}}$ \\
\hline 50 & 2.05 & 72.670 & 45.779 & 34.936 & 22.008 & 13.864 & 10.580 & 8.734 \\
\hline 25 & 1.75 & 63.088 & 39.743 & 30.330 & 19.106 & 12.036 & 9.185 & 7.582 \\
\hline 10 & 1.28 & 50.683 & 31.928 & 24.366 & 15.349 & 9.669 & 7.379 & 6.091 \\
\hline 5 & 0.84 & 41.273 & 26.000 & 19.842 & 12.500 & 7.874 & 6.009 & 4.960 \\
\hline 2 & $-1 \mathrm{E}-07$ & 27.874 & 17.559 & 13.400 & 8.442 & 5.318 & 4.058 & 3.350 \\
\hline
\end{tabular}

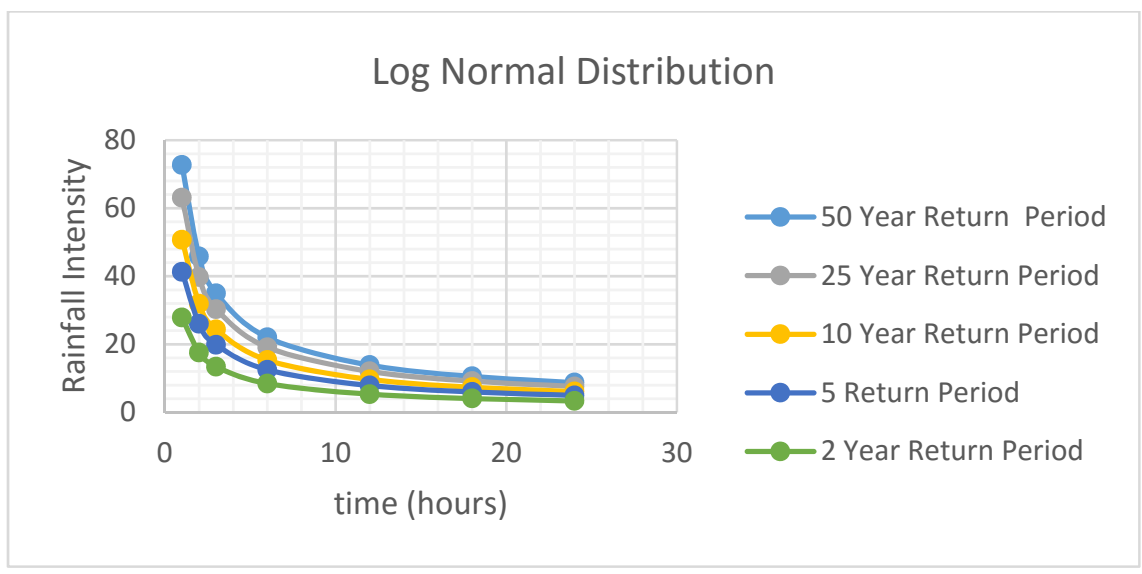

Figure 2: Intensity duration frequency curves for log normal distribution.

Table 3: $\quad$ Rainfall intensity computed from GEV Type 1.

\begin{tabular}{|c|c|c|c|c|c|c|c|c|}
\hline$\underline{\text { Return periods }}$ & $\underline{\boldsymbol{K}}$ & $\underline{\mathbf{1 - h} \boldsymbol{r}}$ & $\underline{\mathbf{2 - h} \boldsymbol{r}}$ & $\underline{\mathbf{3 - h} \boldsymbol{r}}$ & $\underline{\mathbf{6 - h} \boldsymbol{r}}$ & $\underline{\mathbf{1 2 - h} \boldsymbol{r}}$ & $\underline{\mathbf{1 8 - h} \boldsymbol{r}}$ & $\underline{\mathbf{2 4 - h} \boldsymbol{r}}$ \\
\hline 50 & 2.59 & 71.15 & 44.82 & 34.21 & 21.55 & 13.58 & 10.36 & 8.55 \\
\hline 25 & 2.04 & 62.68 & 39.48 & 30.13 & 18.98 & 11.96 & 9.13 & 7.53 \\
\hline 10 & 1.30 & 51.25 & 32.29 & 24.64 & 15.52 & 9.78 & 7.46 & 6.16 \\
\hline 5 & 0.72 & 42.21 & 26.59 & 20.29 & 12.78 & 8.05 & 6.15 & 5.07 \\
\hline 2 & -0.16 & 28.55 & 17.99 & 13.73 & 8.65 & 5.45 & 4.16 & 3.43 \\
\hline
\end{tabular}




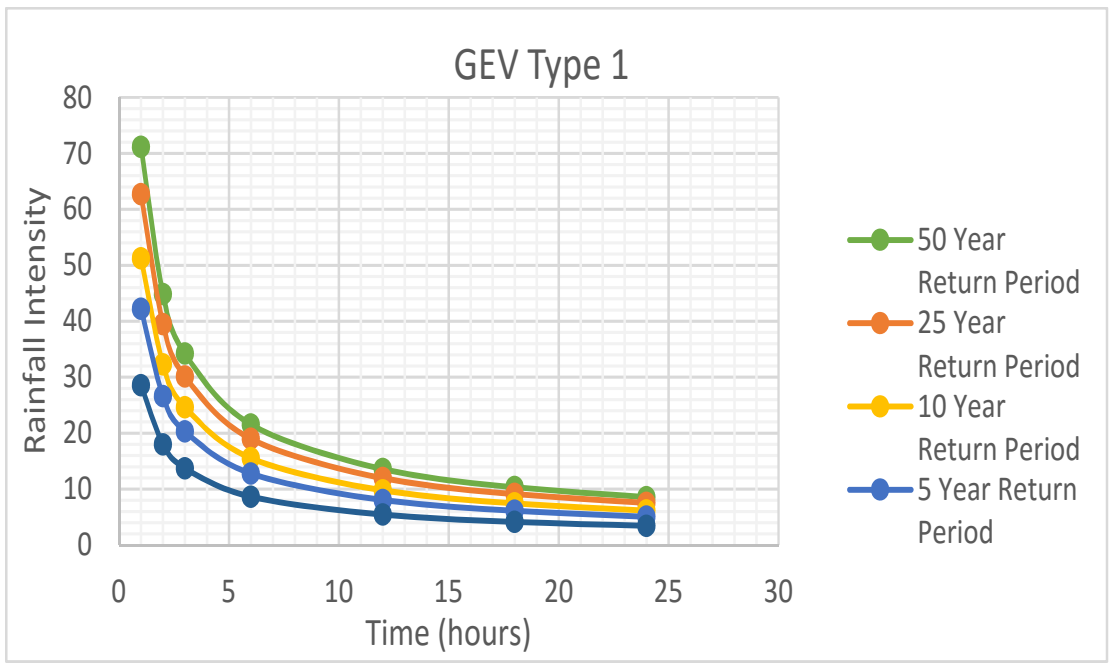

Figure 3: Intensity duration frequency curves for GEV distribution.

Table 4: Rainfall intensity computed from log Pearson distribution.

\begin{tabular}{|c|c|c|c|c|c|c|c|}
\hline$\underline{\text { Return period }}$ & $\underline{\mathbf{1 - h} \boldsymbol{r}}$ & $\underline{\mathbf{2 - h} \boldsymbol{r}}$ & $\underline{\mathbf{3 - h} \boldsymbol{r}}$ & $\underline{\mathbf{6 - h} \boldsymbol{r}}$ & $\underline{\mathbf{1 2 -} \boldsymbol{h} \boldsymbol{r}}$ & $\underline{\mathbf{1 8 - h} \boldsymbol{r}}$ & $\underline{\mathbf{2 4 -} \boldsymbol{h} \boldsymbol{r}}$ \\
\hline 50 & 74.48 & 46.32 & 37.58 & 23.67 & 14.91 & 11.38 & 8.95 \\
\hline 25 & 64.09 & 40.37 & 31.74 & 19.99 & 12.59 & 9.61 & 7.70 \\
\hline 10 & 50.92 & 32.08 & 24.67 & 15.54 & 9.79 & 7.47 & 6.12 \\
\hline 5 & 41.16 & 25.93 & 19.68 & 12.39 & 7.81 & 5.96 & 4.94 \\
\hline 2 & 27.65 & 17.42 & 13.09 & 8.24 & 5.19 & 3.96 & 3.32 \\
\hline
\end{tabular}

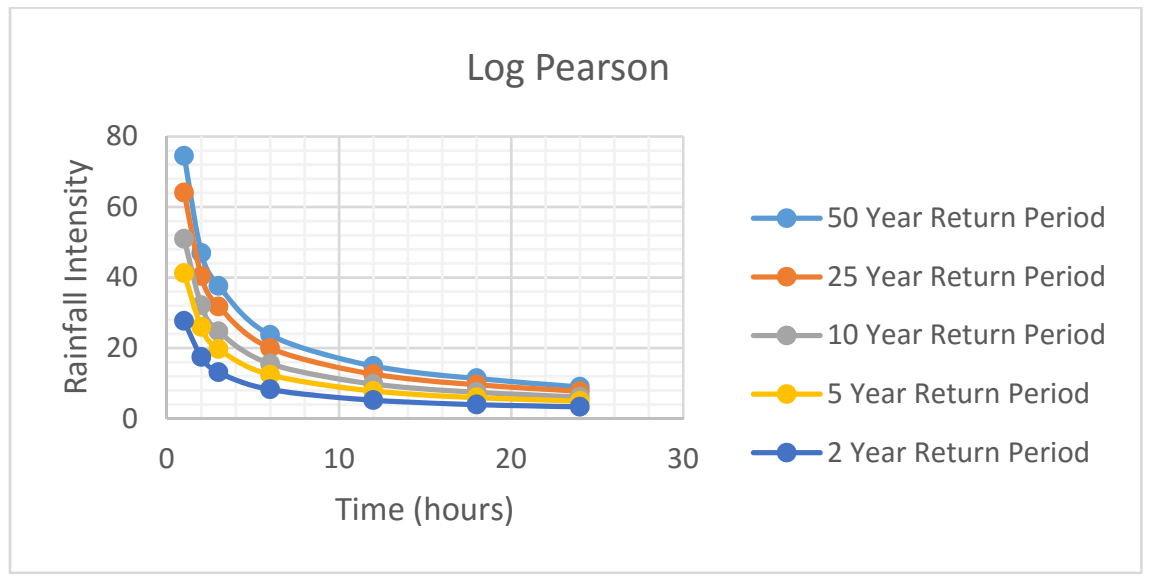

Figure 4: Intensity duration frequency curves for log Pearson distribution. 


\subsection{Empirical formulas}

Rainfall intensity is written as a function of return period and storm duration, as told in eqn (10).

$$
I=\frac{C T r^{m}}{T d^{e}}
$$

In this equation, $\mathrm{Tr}$ represents the return period which is controls the value of $\mathrm{K}$, frequency factor. $\mathrm{Td}$ represent the storm duration. In this equation $\mathrm{C}, \mathrm{m}$ and e are the parameters needed to be calculated. By converting the equation into linear equation, we can calculate the value of the parameters.

1. Logarithmic function is applied to the equation to get eqn (11).

$$
\begin{gathered}
\log I=\log K-e \log T d \\
K=C \operatorname{Tr}^{m}
\end{gathered}
$$

2. Log of base 10 is used to find the log value of intensity and storm duration. The line is plotted on the graph, with log of intensity (yaxis) and log storm duration (x-axis). Slope of line represents the value of parameter e. A separate line is obtained for each return period. Log $\mathrm{K}$ in the line represents the $\mathrm{y}$ intercept.

3. Eqn (12) is converted into linear eqn (13) using the log of base 10.

$$
\log k=\log c+m \log T r
$$

4. Above equation is plotted and the value of $\mathrm{m}$ and $\mathrm{C}$ are obtained. Log $\mathrm{K}$ from previous equation is graph is used with their respective return periods.

5. This procedure is repeated for each distribution.

\subsection{Goodness of fit}

A goodness of fit test is between the observed and expected values as told in Walpole and Myers [9]. Rainfall intensities obtained from each distribution are tested against the rainfall intensities calculated using empirical formulas derived from the data. Chi square test is incorporated in order to compare the observed and experimental values. Observed values are the rainfall intensities value obtained from the distributions and experimental values are the rainfall intensities values calculated from the empirical formula Chin [10]. In order to get the value of chi square for each distribution, following eqn (14) is used:

$$
\text { Chi Square }=\frac{(\text { Obs.-Exp. })^{2}}{\text { Exp. }}
$$


Table 5: Empirical formula derived for probability distributions.

\begin{tabular}{|c|c|c|c|c|c|}
\hline$\underline{\text { Distribution }}$ & $\underline{\boldsymbol{C}}$ & $\underline{\boldsymbol{m}}$ & $\underline{\boldsymbol{e}}$ & $\underline{\boldsymbol{F o r m u l a}}$ & $\underline{\boldsymbol{R}^{2}}$ \\
\hline $\begin{array}{c}\text { Normal } \\
\text { distribution }\end{array}$ & 30.64 & 0.25 & 0.67 & $\frac{30.64 T r^{0.25}}{T d^{0.67}}$ & 0.9398 \\
\hline $\begin{array}{c}\text { Log Normal } \\
\text { distribution }\end{array}$ & 19.78 & 0.32 & 0.67 & $\frac{19.78 T r^{0.32}}{T d^{0.67}}$ & 0.9718 \\
\hline $\begin{array}{c}\text { GEV Type I } \\
\text { Log Pearson } \\
\text { Type III }\end{array}$ & 21.64 & 0.32 & 0.67 & $\frac{21.64 T r^{0.32}}{T d^{0.67}}$ & 0.9626 \\
\hline
\end{tabular}

Table 6: Chi Square test values between empirical formulas and probability distributions values.

\begin{tabular}{|c|c|c|c|c|c|c|c|}
\hline Distribution & $\underline{\mathbf{l - h} \boldsymbol{r}}$ & $\underline{\mathbf{2 - h} \boldsymbol{r}}$ & $\underline{\mathbf{3 - h} \boldsymbol{r}}$ & $\underline{\mathbf{6 - h} \boldsymbol{r}}$ & $\underline{\mathbf{1 2 -} \boldsymbol{h}}$ & $\underline{\mathbf{1 8 -} \boldsymbol{h}}$ & $\underline{\mathbf{2 4 -} \boldsymbol{h} \boldsymbol{r}}$ \\
\hline Normal & 12.29 & 7.58 & 5.71 & 3.52 & 2.17 & 1.63 & 1.34 \\
\hline Log Normal & 6.27 & 4.07 & 3.16 & 2.05 & 1.33 & 1.03 & 0.86 \\
\hline GEV & 2.58 & 1.69 & 1.32 & 0.86 & 0.56 & 0.44 & 0.37 \\
\hline Log Pearson & 1.08 & 0.65 & 0.28 & 0.17 & 0.10 & 0.08 & 0.10 \\
\hline
\end{tabular}

\section{Results}

Normal distribution, lognormal distribution, GEV Type I distribution and Log Pearson distribution were applied to the processed rainfall data, and rainfall intensities were obtained in relation to return period and storm duration. Results show that rainfall intensity increases with increase in return period and decreases with increase in storm duration. Tables $1-4$ show the rainfall intensities calculated in relationship to return period and storm duration using the respective probability distributions. Table 5 shows the value of constants $\mathrm{C}$, e and $\mathrm{m}$ used in the empirical formula of rainfall intensity. $\mathrm{R}^{2}$ value is calculated for the empirical formulas, while calculating values of parameters. All distributions show $\mathrm{R}$ square value greater than $90 \%$, which shows that all empirical formulas fit the model well. Figures 1-4 show the intensity duration frequency curves plotted with storm duration on the $\mathrm{x}$-axis and rainfall intensity on $\mathrm{y}$-axis.

Results of chi square tests show the goodness of fit of the distribution in deriving out the rainfall data. Results of test show the null hypothesis that the extreme rainfall from all distribution is acceptable at the $5 \%$ level of significance. 
Log Pearson being the superior distribution in developing IDF curves, followed by GEV type 1, lognormal distribution and normal distribution.

\section{References}

[1] "List of Meteorological Observatories," [Online]. Available: http://www.pmd.gov.pk/Observatories/index.html. [Accessed 12 March 2016].

[2] R. Chowdary, "Short Duration Rainfall Estimation of Sylhet: IMD and USWB Method," Journal of Indian Water Works Association, pp. 285-292, 2007.

[3] M. M. Rashid, S. B. Faruque and J. B. Alam, "Modeling of Short Duration Rainfall Intensity Duration Frequency (SDR-IDF) Equation for Sylhet City in Bangladesh," ARPN Journal of Science and Technology, vol. 2, no. 2, pp. 92-95, 2012.

[4] F. Y. Logah, K. Kankam-Yeboah and E. O. Bekoe, "Developing Short Duration Rainfall Intensity Frequency Curves for Accra in Ghana," International Journal of Latest Research In Engineering and Computing (IJLREC), vol. 1, no. 1, pp. 67-73, 2013.

[5] M. M. Rasel, "Modeling of Rainfall Intensity Duration Relationship for Seven Divisions of Bangladesh Using LPT III Method," International Conference on Recent Innovation in Civil Engineering for Sustainable Development, pp. 1045-1049, 2015.

[6] M. T. Sinan Jasim Hadi, "Developing an empirical formula for estimating rainfall intensity by developing Intensity-Duration-Frequency relationships," pp. 154-162.

[7] V. T. Chow, Applied Hydrology, McGraw Hill, 1988.

[8] V. T. Chow, "Frequency Analysis," in Applied Hydrology, 1988, p. 392.

[9] R. E. Walpole, R. H. Myers, S. L. Myers and K. Ye, Probability and Statistics for Engineers \& Scientists, Boston: Prentice Hall, 2012.

[10] D. A. Chin, Water Resources Engineering, Edinburgh: Pearson Education Limited, 2013. 